\title{
Bibliometric Analysis of Green Energy Research from 2011 to 2017
}

\author{
A. D. Arenas ${ }^{1}$, G. E. Valencia ${ }^{2}$ and J. E. Duarte ${ }^{3^{*}}$ \\ 'Department of Mechanical Engineering, Universidad del Atlantico, Km 7 Antigua Via a Puerto \\ Colombia, Barranquilla, Colombia; aarenas@mail.uniatlantico.edu.co \\ ${ }^{2}$ Department of Mechanical Engineering, KAI Research Group, Universidad del \\ Atlantico, Barranquilla, Colombia; guillermoevalencia@mail.uniatlantico.edu.co \\ ${ }^{3}$ Department of Mechanical Engineering, DIMER Research Group, Universidad \\ del Atlantico, Barranquilla, Colombia; jorgeduarte@mail.uniatlantico.edu.co
}

\begin{abstract}
Background/Objectives: To make Bibliometric analysis on green energy for the period 2011-2017, based on the science citation index database. Methods: The search identified a total of 1000 publication related to green power at this time, publication output patterns, significant journals, international productivity, geographical distribution of authors and author keywords were analyzed using the Histcite software. Findings: The number of publications on green energy increased from 61 in 2011 to 234 in 2016, so far in 2017, a total of 174 papers have been written. Renewable \& sustainable energy reviews $(37 ; 3.7 \%)$ was the journal with the highest number of documents, followed by applied energy (30.3\%) and energy and building $(29 ; 2.9 \%)$. China led the productivity ranking with 227 articles, USA ranked second with a total of 187, followed by the UK with 72. The most productive institution was the Chinese Academy Science with a total of 36 publications, developed by University of Chinese Academy of Sciences with 14 and Universiti Teknologi Malaysia with 13. The principal authors' groups concentrated in China and the USA, these countries being the ones that produce the most publications. Green Energy remains the most critical keywords in the period 2011 to 2017, it was noticed a significant increase in the search for keywords after 2014 due to the energy crisis and environmental protection campaigns that have been developing since that year. Application: Statistical methods were used in this work in order to analyze the evolution, and the historical development of the green energy subject, involving some relevant aspect such as the patterns of authorship, volume of publication and citation study.
\end{abstract}

Keywords: Bibliometrics, Efficiency, Energy, Green, Impact Factor, Publications

\section{Introduction}

Globalization takes the modern world towards green energy sources. Green energy is a clean energy source that has a lower environmental impact compared to conventional energy technology $y^{1,2}$. The use of natural resources with a green environment and sustainability has become the critical issue of global society ${ }^{3}$, where sustainable energy resources such as solar cells, wind power, and wave energy have been promising targets ${ }^{4}$. Technological advances in renewable energies have extended their use globally, as the sources of these energies are available worldwide in contrast to conventional sources such as gas, coal, and oil that geographically concentrated in some countries ${ }^{5,6}$. In contrast, all countries in the world have at least one source of renewable energy and many states have a portfolio of renewable energy sources ${ }^{3}$. In 2006 , solar power cost US $\$ 600 / \mathrm{MWh}$, while the price of traditional coal and natural gas was only US\$100/MWh. In 2016, the cost of solar power was US\$ 100/MWh, and

*Author for correspondence 
the wind energy cost of US\$50/MWh ${ }^{4}$. A considerable drop in its price, in the last report obtained by Bloomberg in 2015, it was known that the Asia-Pacific region (APAC) invested US\$ 179,000 million for a total of US\$329,000 million and the least invested was Europe (EMEA) with 79,000 million $^{7}$ as shown in Figure 1. Research on green energy has produced a large number of publications by authors around the world ${ }^{8-11}$. However, there have been few attempts to collect systematic data on global scientific research on green energy ${ }^{12-14}$. A standard research tool is a bibliometric analysis that has already widely used in production studies and trend research in many disciplines of science and engineering ${ }^{15,16}$. The bibliometric analysis evaluates the academic results of authors, institutions, and countries and identifies the temporal evolution of research patterns ${ }^{17-19}$. In this work, a bibliometric analysis of green energy was carried out from 2011 to 2017. This study aimed to reveal trends in scientific outputs, distribution characteristics and provide potential guidance for future research on green energy.

\section{Methodology}

The data was taken from the online versions of the Scientific Citation Index (SCI) accessed through the Web of Science. It was necessary to obtain the metadata of the articles, to do this, the keywords of different items were used to collect the metadata. Once the metadata was received, a program called HistCite was used to enter the metadata and give us all the necessary information to carry out the analysis. All publications identified in the ICS database related to green energy evaluated against the following criteria: publication outputs; characteristics and main journals; productivity; geographic distribution of books; and author's keywords. Contributions from different institutions and countries determined by their number of global citations (TGCS) and this, in turn, was related to the factor of impact (FI).

\section{Results and Discussion}

\subsection{Publication Output}

From 2011 to 2017, a total of 1000 publication related to green energy identified, the annual number of green energy publications increased from 61 in 2011 to 234 in 2016, so far in 2017, a total of 174 have been written. Cumulative progression was represented by an exponential model (Figure 2). A high determination coefficient produced for the data collected $\left(R^{2}=0.997\right)$. One could conclude that the number of articles referring to green energy is growing at a high rate. The y-axis is the increas-

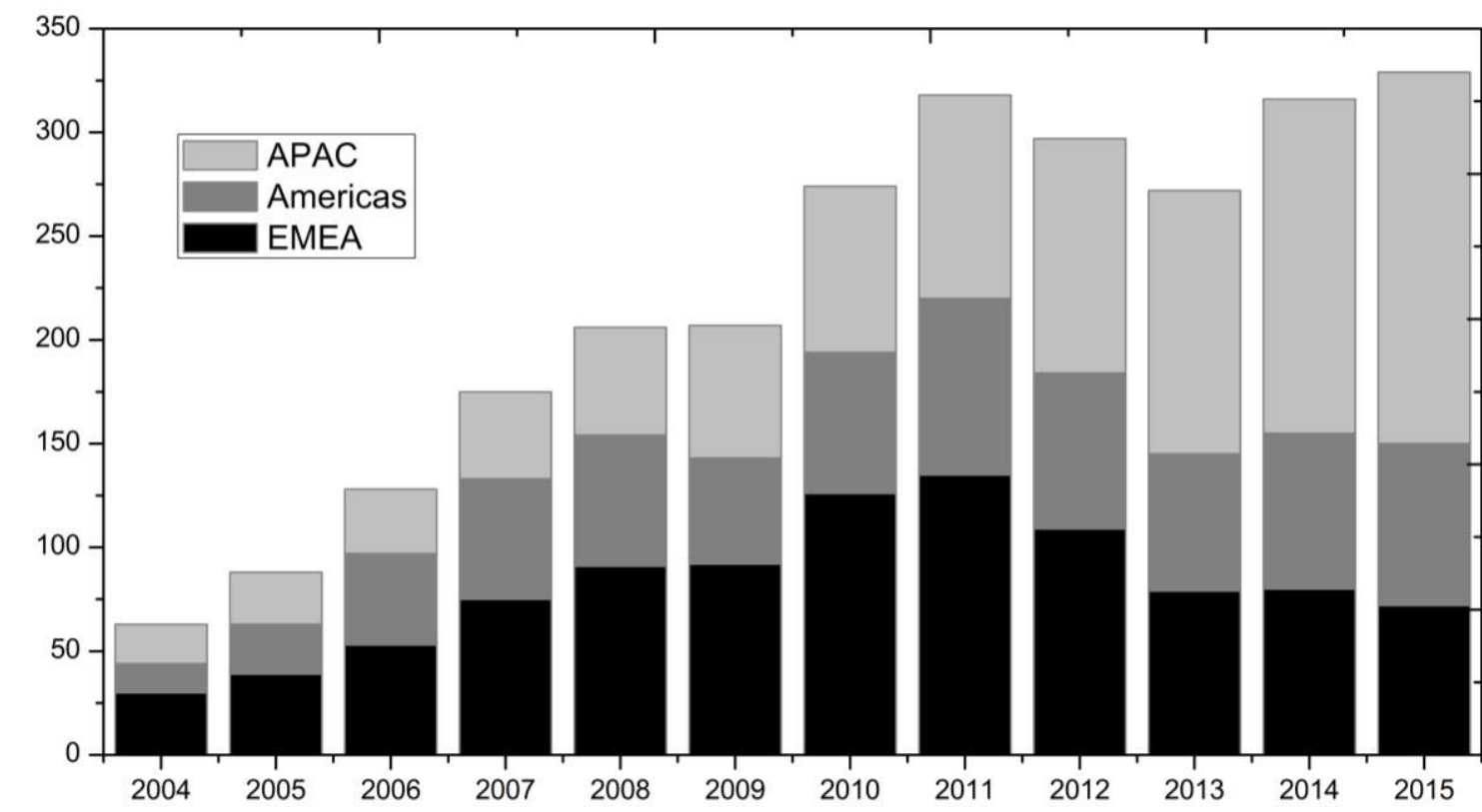

Figure 1. Investments by region in green energy. 


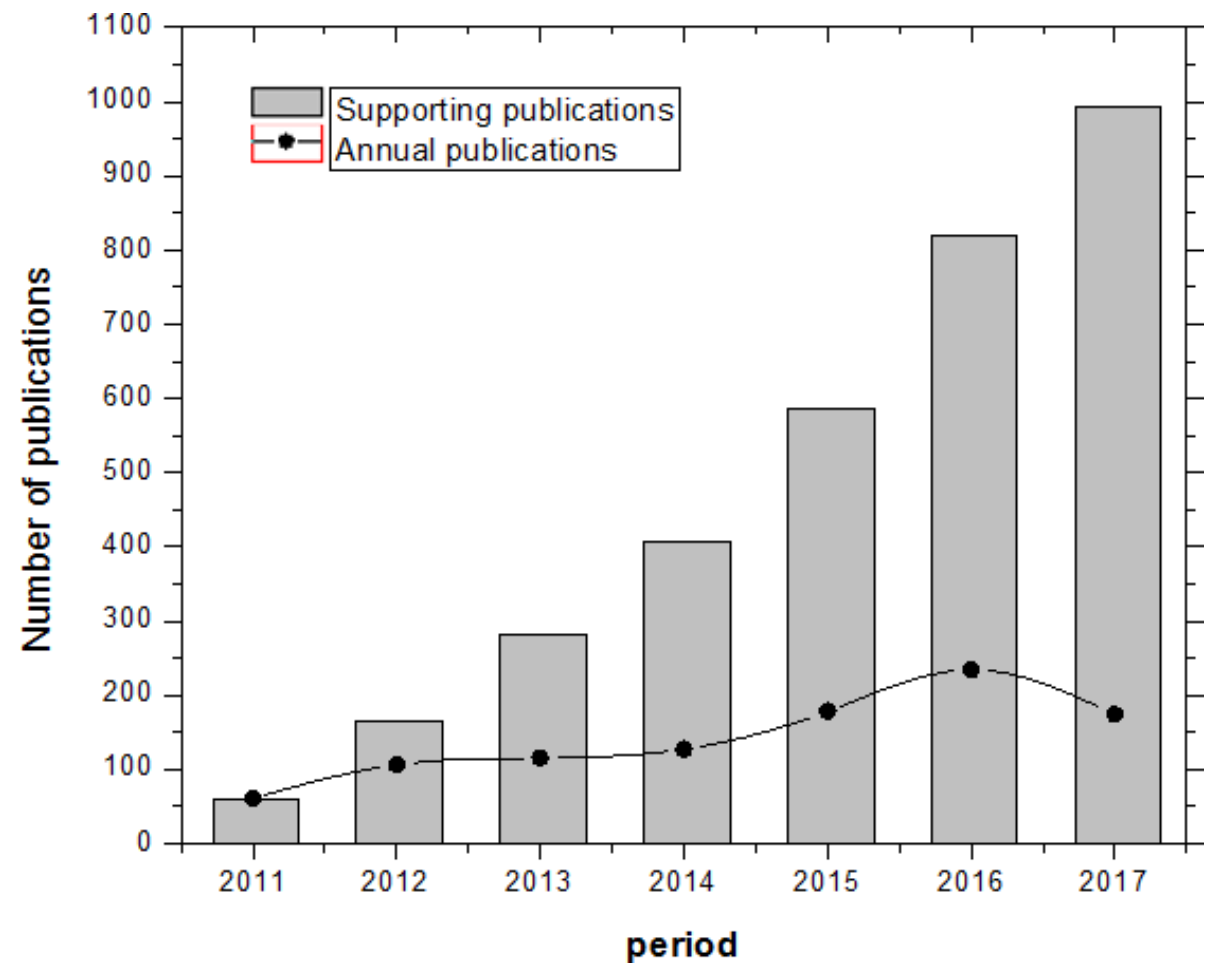

Figure 2. Years vs. Number of cumulative publications.

ing number of papers, and the $\mathrm{x}$-axis is the number of years since 2011. Nine types of documents found in all books related to green energy in the period 2011-2017. The article was the most frequent type of document, comprising $81.9 \%$ of total production. Followed by review (61; 6.1\%), editorial material $(44 ; 4.4 \%)$, proceedings paper $(21 ; 2.1 \%)$, meeting Abstract $(21 ; 2.1 \%)$ and book review (16;1.6\%). $98.8 \%$ of all journal articles published in English (988), followed by French (2), German (2), Polish (2) and Portuguese (2).

\subsection{Main Journal}

The number of journals publishing research related to green energy increased from 61 in 2011 to 497 in 2017. With the distribution of output in the top 10 journals, renewable \& sustainable energy reviews (37; 3.7\%) being the journal with the highest number of publications, followed by applied energy (30.3\%) and energy and building $(29 ; 2.9 \%)$. The impact factor (IF) is used to assess the relative importance of a journal, however, when used as an indicator of article quality if it can overestimate the value of minor articles at the expense of more significant impact. The factor of impact (FI) can be calculated as (TGCS/TP) where TP corresponds to the total number of publications, and TGCS to the total number of global citations. Renewable \& sustainable energy reviews have the most citations with (127) and an FI of 3.44 while renewable energy has the fewest citations with (45) but an FI of 4.14 much higher than the first journal on the list as shown in Table 1.

\subsection{Productivity and Publications at the International Level}

The results indicate that the contribution by country was estimated taking into account the total number of books as shown in Table 2; China led the productivity ranking with 227 papers. USA ranked second with a total of 187 , followed by the UK, Canada, India, and others.

The production by countries shows China with the most significant number of total publications 227, but USA is the country that has more citations with 3645 , the state that has generated the most significant impact with its papers according to the factor of impact is France with a $\mathrm{FI}=32.65$. The collaboration network of the $11 \mathrm{most}$ 
Table 1. Top 10 distribution of the journal, TP (total publications), TGCS (global quotations), FI (Factor of impact) according Scimago Journal \& Country Rank ${ }^{20}$

\begin{tabular}{|c|c|c|c|}
\hline Journal & Records & TGCS & FI \\
\hline RENEWABLE \& SUSTAINABLE ENERGY REVIEWS & 37 & 127 & 3.44 \\
\hline APPLIED ENERGY & 30 & 110 & 3.68 \\
\hline ENERGY AND BUILDINGS & 29 & 89 & 3.09 \\
\hline ENERGY POLICY & 22 & 44 & 2.00 \\
\hline ENERGY & 16 & 47 & 2.95 \\
\hline PAPERS OF THE AMERICAN CHEMICAL SOCIETY & 15 & 0 & 0.00 \\
\hline IEEE JOURNAL ON SELECTED AREAS IN COMMUNICATIONS & 14 & 46 & 3.32 \\
\hline JOURNAL OF CLEANER PRODUCTION & 13 & 13 & 1.02 \\
\hline RENEWABLE ENERGY & 11 & 45 & 4.15 \\
\hline IEEE COMMUNICATIONS JOURNAL & 10 & 62 & 6.22 \\
\hline
\end{tabular}

Table 2. Top 11 most productive countries 2011-2017 TGCS (citations global totals), FI (Factor of impact)

\begin{tabular}{|l|l|l|l|}
\hline Countries & Total records & TGCS & FI \\
\hline China & 227 & 3101 & 13.66 \\
\hline USA & 187 & 3645 & 19.49 \\
\hline UK & 72 & 794 & 11.03 \\
\hline Canada & 67 & 779 & 11.63 \\
\hline India & 59 & 294 & 4.98 \\
\hline South Korea & 56 & 654 & 11.68 \\
\hline Italy & 48 & 756 & 15.75 \\
\hline Germany & 47 & 704 & 14.98 \\
\hline France & 43 & 1404 & 32.65 \\
\hline Taiwan & 34 & 533 & 15.68 \\
\hline Malaysia & 32 & 539 & 16.84 \\
\hline
\end{tabular}

productive countries shown in Figure 3. Each point represents a country/territory, and interconnection lines represent the strength of collaboration considering the number of global citations (TGCS). As can be seen, USA took the central part of the collaboration network although it has a lower production of publications that China presents a higher number of global citations this makes USA as the primary partner among the most productive countries, including China, UK, and Canada.

The most prolific institution was Chinese Academy Science with 36 documents, followed by University of Chinese Academy of Sciences with 14 papers and Universiti Teknologi Malaysia with 13 articles. Seven research centers belong to China and three to Malaysian, as shown in Table 2. Can see that many countries do not have schools in the top 10 of production (Table 3). These which indicates that the creation of articles in the rest of nations is scattered and that there are many more institutions that are dedicated to green energy research than those that exist in Chinese and Malaysian.

The $\mathrm{CP} \%$ represents the collaborative network of most productive institutions in Table 3; each value represents the amount of input from that institution in the development and evolution of the topic. We found that institutions in the same country tend to have a higher rate of collaboration, for example, the Chinese Academy of Sciences and University of Chinese Academy of Sciences.

\subsection{Geographical Distribution of Authors}

Of the 1000 publications from 2011 to 2017.233 (23.32\%) written by two authors, 189 (18.92\%) by three authors, 149 (14.91\%) by one author, 141 (14.11\%) by four authors, 122 (12.21\%) by five authors, 78 (7.81\%) by six authors. The remaining $8.1 \%$ are publications written by seven authors up to 19 authors. The worldwide geographical distribution of authors indicates that the first groupings were in Chinese, USA, UK, and Canada we can also observe the relationship that it has with the number of articles published by countries.

\subsection{Author Keyword}

The author keyword analysis provides information on research trends, revealing areas of interest to researchers. Table 4 lists and classifies the main author keywords that 


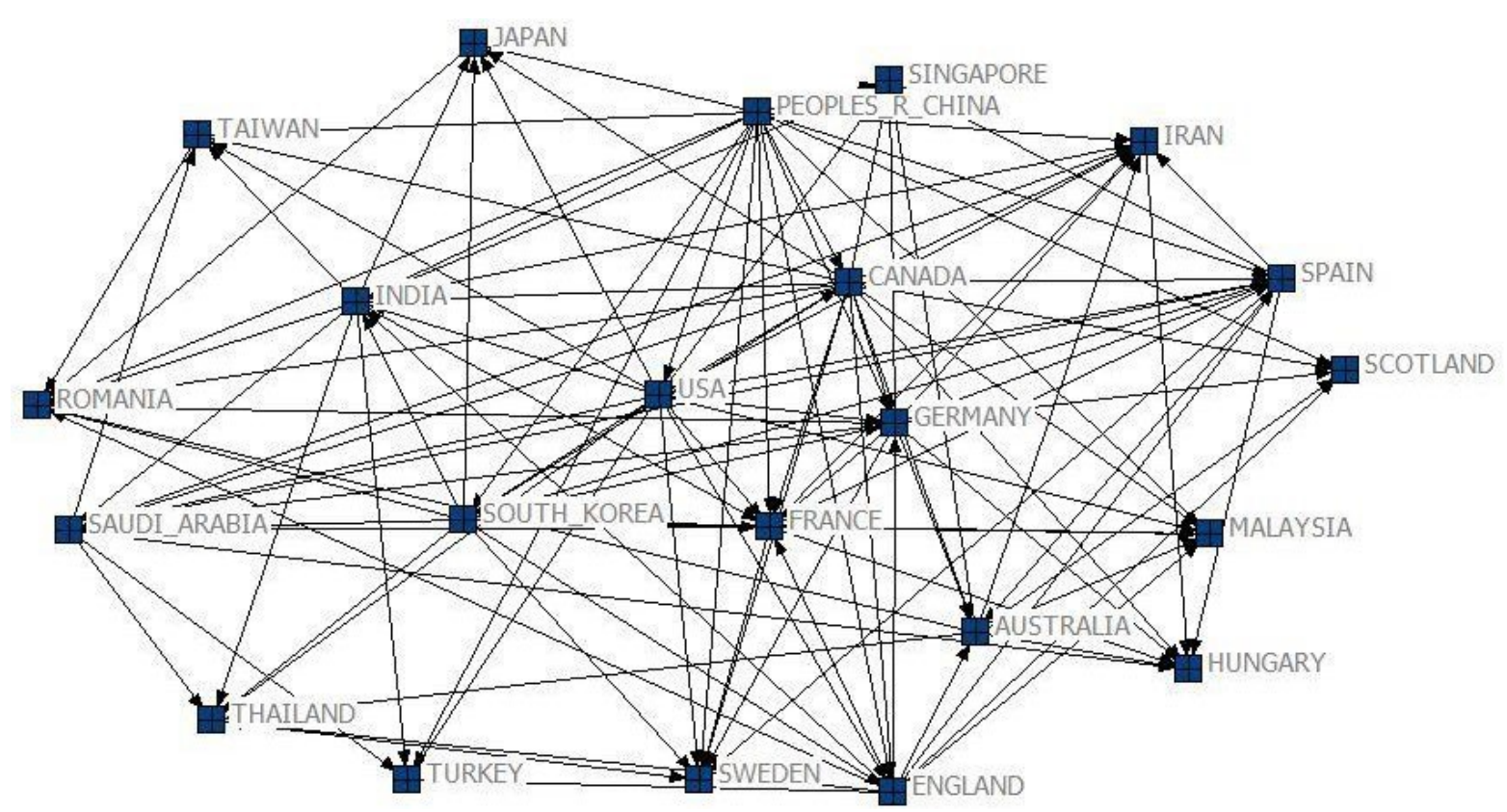

Figure 3. Country collaboration network.

Table 3. Top 10 most productive institutions 2011-2017 Rec (total publications), TGCS (total global citations), CP (international collaboration)

\begin{tabular}{|l|l|l|l|}
\hline Institutions & Rec & TGCS & CP \% \\
\hline ChineseAcadSci & 36 & 741 & 30.51 \\
\hline UnivChineseAcadSci & 14 & 370 & 11.86 \\
\hline UnivTeknol Malaysia & 13 & 351 & 11.02 \\
\hline TsinghuaUniv & 11 & 152 & 9.32 \\
\hline NanyangTechnolUniv & 10 & 262 & 8.47 \\
\hline China UnivGeosci & 9 & 300 & 7.63 \\
\hline Univ Malaya & 9 & 74 & 7.63 \\
\hline Beijing UnivPosts\&Telecommun & 8 & 30 & 6.78 \\
\hline CarletonUniv & 8 & 148 & 6.78 \\
\hline
\end{tabular}

appear in articles between 2011 and 2017. A total of 3012 keywords used in the dataset. During the period studied, some keywords have a high search index, being "energy", the highest index has with a 991 and "green" with an index of 947 , this shows us that in the field of energy is conducting intense research in the period from 2011 to 2017. Table 4 shows the top 20 keywords with which researchers search for publications related to green energy.

In Table 4, the time from 2014 to 2017 shows a significant increase in the number of books; this shows us that since that date and due to the energy crisis and environ- mental problems. Researchers are looking for new ways to obtain energy so that the planet is not affected, making the production of articles on green energy increase significantly.

\section{Conclusions}

A bibliometric analysis of the output patterns of publications, significant journals, international productivity, the geographical distribution of authors and author keywords on documents related to green energy was carried out from 2011 to 2017. Our research yielded several significant trends in global research performance over the period. In total, 1000 publications published in the period 2011-2017. Books added year after year, the annual growth rate of papers in green energy research is $82.75 \%$. Renewable \& sustainable energy reviews, applied energy and energy and the building was the three best journals with the highest number of publications on green energy. China and the USA were the countries that produced the most papers.

Also, those that had the most significant amount of citations at a global level, France although with fewer books and quotes is one that has the highest factor of impact. The primary spatial groupings of authors were in China, USA, and the UK, with several smaller groups in the rest of the world. The author's keyword analysis pro- 
Table 4. Top 20 author keywords in 6 years. Rec is the total publications, PAG publications by period of study and $\mathrm{R}$ is the rank

\begin{tabular}{|c|c|c|c|c|c|c|}
\hline \multirow[t]{2}{*}{ Authorkeywords } & \multirow[t]{2}{*}{$\operatorname{Rec}$} & \multirow[t]{2}{*}{$\operatorname{Rec} \mathbf{R}(\%)$} & \multicolumn{2}{|c|}{ 2011-2013 } & \multicolumn{2}{|c|}{\begin{tabular}{|l|} 
2014-2017 \\
\end{tabular}} \\
\hline & & & PAG & R (\%) & PAG & R (\%) \\
\hline Energy & 991 & 35.28 & 282 & 28.46 & 709 & 71.54 \\
\hline Green & 947 & 33.71 & 360 & 38.01 & 587 & 61.99 \\
\hline Transfer & 88 & 3.13 & 20 & 22.73 & 68 & 77.27 \\
\hline Based & 78 & 2.78 & 14 & 17.95 & 64 & 82.05 \\
\hline Efficient & 74 & 2.63 & 18 & 24.32 & 56 & 75.68 \\
\hline Networks & 72 & 2.56 & 20 & 27.78 & 52 & 72.22 \\
\hline Efficiency & 62 & 2.21 & 14 & 22.58 & 48 & 77.42 \\
\hline Renewable & 62 & 2.21 & 14 & 22.58 & 48 & 77.42 \\
\hline Systems & 50 & 1.78 & 16 & 32.00 & 34 & 68.00 \\
\hline Using & 48 & 1.71 & 14 & 29.17 & 34 & 70.83 \\
\hline High & 46 & 1.64 & 10 & 21.74 & 36 & 78.26 \\
\hline Performance & 45 & 1.60 & 6 & 13.33 & 39 & 86.67 \\
\hline TB3 & 45 & 1.60 & 9 & 20.00 & 36 & 80.00 \\
\hline Building & 43 & 1.53 & 8 & 18.60 & 35 & 81.40 \\
\hline Power & 43 & 1.53 & 19 & 44.19 & 24 & 55.81 \\
\hline Sustainable & 40 & 1.42 & 13 & 32.50 & 27 & 67.50 \\
\hline Saving & 39 & 1.39 & 8 & 20.51 & 31 & 79.49 \\
\hline Emitting & 36 & 1.28 & 10 & 27.78 & 26 & 72.22 \\
\hline
\end{tabular}

vides information on research trends, areas of research interest in the field of green energy that reveals "energy", "green", "efficiency" and "renewable" are growing along with green energy research. In the period from 2011 to 2013 can be seen how production was lower than the time from 2014 to 2017, which shows a vast increase in the interest that researchers have in green energy.

\section{Acknowledgment}

This research was supported by Engineering Department of Universidad del Atlantico. In part by the Efficient Energy Management Research Group Kai, with G. Valencia, and by the DIMER Research Group, with J. Duarte, both from Mechanical Engineering Program.

\section{References}

1. Rodprasert R, Chandarasupsang T, Chakpitak N, Yupapin PP. Green Energy Community with smart society for sustainable living. Energy Procedia. 2014; 56:678-89. crossref.
2. Tebyetekerwa M, Wang X, Marriam I, Dan P, Yang S, Zhu M. Green approach to fabricate Polyindole composite nanofibers for energy and sensor applications. Materials Letters. 2017; 209:400-3. crossref.

3. Curley A. A failed green future: Navajo Green Jobs and energy "transition" in the Navajo Nation. Geoforum. 2018; 88:57-65. crossref.

4. Oncel SS. Green energy engineering: Opening a green way for the future. Journal of Cleaner Production. 2017; 142:3095-100. crossref.

5. Koseoglu MA, Rahimi R, Okumus F, Liu J. Bibliometric studies in tourism. Annals of Tourism Research. 2016; 61:180-98. crossref.

6. Akermi R, Triki A. The green energy transition and civil society in Tunisia: Actions, motivations and barriers. Energy Procedia. 2017; 136:79-84. crossref.

7. Byrne J, Hughes K, Rickerson W, Kurdgelashvili L. American policy conflict in the greenhouse: Divergent trends in federal, regional, state, and local green energy and climate change policy. Energy Policy. 2007; 35(9):4555-73. crossref.

8. Merigo JM, Pedrycz W, Weber R, Sotta C. Fifty years of Information Sciences: A bibliometric overview. Information Sciences. 2018; 432:245-68. crossref. 
9. Merigo JM, Yang JB. A bibliometric analysis of operations research and management science. Omega. 2017; 73:37-48. crossref.

10. Dao SD, Abhary K, Marian R. A bibliometric analysis of Genetic Algorithms throughout the history. Computers \& Industrial Engineering. 2017; 110:395-403. crossref.

11. Cancino C, Merigo JM, Coronado F, Dessouky Y, Dessouky M. Forty years of Computers \& Industrial Engineering: A bibliometric analysis. Computers \& Industrial Engineering. 2017; 113:614-29. crossref.

12. Laengle S, Merigo JM, Miranda J, Slowinski R, Bomze I, Borgonovo E, Teunter R. Forty years of the European Journal of Operational Research: A bibliometric overview. European Journal of Operational Research. 2017; 262(3):803-16. crossref.

13. Zeng R, Chini A. A review of research on embodied energy of buildings using bibliometric analysis. Energy and Buildings. 2017; 155:172-84. crossref.

14. Van Nunen K, Li J, Reniers G, Ponnet K. Bibliometric analysis of safety culture research. Safety Science. 2017. crossref.
15. Almind TC, Ingwersen P. Info metric analyses on the World Wide Web: methodological approaches to 'webometrics'. Journal of Documentation. 1997; 53(4):404-26. crossref.

16. Kashkoush A, Prabhu AV, Tonetti D, Agarwal N. The Neurosurgery Match: A Bibliometric Analysis of 206 FirstYear Residents. World Neurosurgery. 2017; 105:341-7. crossref. PMid:28578112.

17. Wang B, Yang Q, Yang LT, Zhu C. On minimizing energy consumption cost in green heterogeneous wireless networks. Computer Networks. 2017; 129:522-35. crossref.

18. Apriliyanti ID, Alon I. Bibliometric analysis of absorptive capacity. International Business Review. 2017; 26(5):896907. crossref.

19. Li X, Wu P, Shen GQ, Wang X, Teng Y. Mapping the knowledge domains of Building Information Modeling (BIM): A bibliometric approach. Automation in Construction. 2017; 84:195-206. crossref.

20. Scimago Journal \& Country Rank. Available from: crossref. 